\title{
Promoting Teaching Effectiveness by Diversification of Evaluation Methods: A Case Study of World Trade Organization Bilingual Course for International Trade Major
}

\author{
Chanting Chen ${ }^{1, a}$ \\ ${ }^{1}$ East China University of Political Science and Law, Shanghai, China \\ achenchanting@126.com
}

Keywords: Evaluation Methods, Diversification, World Trade Organization, Bilingual Course

\begin{abstract}
Bilingual education has been encouraged by the Ministry of Education in China with the opening up of the country. Yet the actual bilingual teaching effect is to be strengthened. The author, based on the positive correlation between examination and teaching effect, diversifies evaluation methods for World Trade Organization bilingual course, so as to reward students' efforts at ordinary time and to encourage them to participate classroom activities more actively. This paper explains the evaluation methods and the actual implementation effect. The teaching experiment receives expected result, illustrating that bilingual education should pay more attention to students' daily performance.
\end{abstract}

\section{Introduction}

The reform of curriculum evaluation system in colleges and universities can help improve the teaching quality. Norman E. Gronlund points out that in order to achieve teaching effectiveness, evaluation system should be considered as an essential part of teaching activities, so as to form a complete process of teaching, learning and evaluation. [1] Teaching refers to educators' activities of imparting knowledge. Learning refers to students' activities of acquiring knowledge. Evaluation means that teachers assess students' mastery of curriculum knowledge.

A good evaluation system is able to reflect students' learning situation, and to force teachers to adjust their teaching methods and contents according to students' performance. A good evaluation system can also reflect students' learning effect, so that students can adjust their learning methods in time to achieve better learning results. In addition, course assessment is one of the most important ways to evaluate students' learning effects.

This paper takes the World Trade Organization bilingual course targeting international economics and trade major students as an example. In order to promote students' learning enthusiasm and to strengthen teaching effect, the course adopts a variety of evaluation methods, including final examination, mid-term examination, group presentation, course essay, class participation and class attendance. The diversification of the course evaluation methods are adopted in order to assess students' usual performance, to reduce the weight of the final exam, and to promote teaching effect by arousing students’ learning enthusiasm.

\section{The Necessity of Bilingual WTO Course and the Bottleneck of Traditional Evaluation Methods}

American bilingual education expert R. W. Blair pointed out in 1980s that cultivating a large number of competent bilingual talents is one of the important goals of sustainable development in today's world. [2] The Ministry of Education in China has asked universities to gradually implement bilingual teaching at the undergraduate level. It is especially considered as necessary and feasible to teach international law courses in bilingual way. [3] WTO belongs to international law in subject classification. Also, in consideration of the uniqueness of the course contents, the bilingual form of the WTO course can enable students to acquire more professional terms, and to have more 
opportunities to contact with the first-hand materials, which help them to know a real world trade organization.

However, it is not easy to teach the WTO course in a bilingual way. Part of the reason is that the targeting learning group does not major in law and lacks legal knowledge and way of thinking. Although some students have taken some minor courses in law or elective law courses, others still have no such learning experience. Also in most cases, the learning effect for minor courses is not as good as for major courses. Another reason is due to the unique attributes of the WTO legal system. Because WTO documents are closely related to the interests of sovereign states, the wording of legal provisions of the documents is extremely cautious and difficult to understand. It is therefore difficult for undergraduate students to acquire WTO legal knowledge in English.

Since the nature of the WTO course requires bilingual teaching mode, and it is hard for students to comprehend and command the knowledge, improving students' learning enthusiasm and paying attention to their persistence effort are the way to solve the problem. This further requires an evaluation system specifically designed for the course, which will reward students if they perform well and participate actively in class time. Current course evaluation system cannot meet this requirement. Take the East China University of Political Science and Law (ECUPL), where the author works, as an example. Generally speaking, the course evaluation system consists of final examination and daily performance. The final examination score represents $70 \%$ of the course grade and daily performance represents $30 \%$. The final examination most of the time is a close book test. The daily performance score usually consists of class performance, fulfillment of homework and mid-term examination grade without specific evaluation standards.

Although there is a positive correlation between students' diligence and final exam results, sometimes excessive nervousness does affect students' performance in the examination room. In addition, bilingual examination paper is more difficult than general Chinese one, which leads to a comparatively low average score. On the other hand, the percentage of daily performance is underestimated, and the criterion of daily performance evaluation is ambiguous. Hence current course evaluation system depends too much on the final examination score, while fails to make a quantitative evaluation of students' attitude and efforts of learning at ordinary times. The main function of course assessment is to evaluate how students perform in the course learning process and whether they have grasped the knowledge system of the course. Course assessment is also used to push students study harder. Current evaluation system fails to satisfy the function requirement, particularly in the WTO bilingual course for international economics and trade major students.

\section{Restructure the World Trade Organization Bilingual Course Evaluation System}

There are two major purposes to restructure evaluation system of the WTO bilingual course, to optimize evaluation function and to improving teaching effect. To fulfill these purposes, the new evaluation system consists of six parts, final examination, mid-term examination, course essay, group presentation, class participation and class attendance. The final examination accounts for $40 \%$ of the course grade, the mid-term examination and group presentation represent $15 \%$ of the course grade respectively, and the rest three contents account for $10 \%$ of the course grade respectively. (Diagram I) The division of the restructured evaluation system is more detailed, the inspection is more comprehensive, and the standard is clearer. This will help motivate students to study harder at ordinary times, encourage students to actively participate in classroom activities, and increase the content and flexibility of assessment.

The final and mid-term examinations play an important role in imposing pressure on students, hence remained in the new evaluation system. But for fairness, their proportions have been dropped substantially. The final examination focuses on checking whether students have grasped course knowledge systematically. The mid-term examination is for finding out the teaching and learning effect of the first half of the semester, so as to lay a solid foundation for teaching activities in the second half of the semester. 


\section{Diagram I Evaluation System Structure}

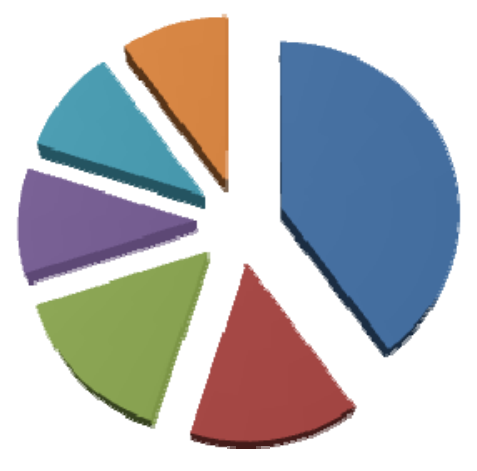

- Final Exam

Mid-term Exam

Group Presentation

- Course Essay

- Class Participation

- Class Attendance

Group presentation divides students into different groups with 4 people as a group. Each group of students will have a specific topic relating to the course, such as how the friend of court mechanism works in WTO dispute settlement system, why there is anti-WTO voice and the rationale of non-violation case, etc. Students are required to search and find necessary reading materials, summarize and reorganize that information into a coherent essay, and present it in class. Group presentation is for examining students' ability of information collection, team work, and oral presentation. Essay writing is for students to explain their opinions on certain hot topics related to WTO. Examples of essay topics include the multilateralism of the WTO dispute settlement system and the fairness and justness of the WTO. This assessment is mainly to encourage students to think creatively on WTO related issues.

WTO course involves a lot of dispute settlement cases. Therefore, lecturers should not only play the roles of organizers and leaders of class activities, but also to some extent let students become masters of learning and display their initiative. [4] Lecturers, as the main line, teach knowledge points systematically, while using case study for further explanation. In case study section, discussions are designed to optimize bilingual teaching effects and to test students' ability of applying knowledge to solve practical problems. Therefore, class participation accounts for $10 \%$ of the total course grade to encourage students to participate in classroom interaction.

In addition, bilingual learning requires students to study in a persistent way. Therefore, class attendance accounts for $10 \%$ of the total course grade, as an encouragement to diligence and with due consideration to fairness. The WTO bilingual course has a fixed seating pattern that enhances interaction between teachers and students and eliminates unnecessary waste of time due to frequent roll call.

\section{Implementation effect of Diversification of Evaluation Methods}

The implementation of diversified assessment methods requires support from the target students. Because the new assessment method effectively pays attention to students' performance and efforts at ordinary times, instead of relying heavily on their final exam performance, it is welcomed by students. More specifically, the mid-term exam focuses on Chinese - English translation of WTO terminology. Because one of the difficulties of learning WTO bilingual course is the mastery of special WTO terms, which directly relate to understanding of classroom instruction and performance in final examination. The mid-term examination helps students find out their weak points, and make up them during the second half semester's study.

The final examination consists of blank filling, true and false, multiple choices, case analysis and essay. The proportion of subjective and objective questions is 1:1. The blank filling and true and false questions focus on the assessment of basic knowledge and is comparatively easy. The multiple choice questions focus on the evaluation of complex knowledge. Because of the uncertainty of the 
number of correct options, multiple choices are the hardest question type. Case analysis is adopted to check whether students can analyze actual cases with acquired knowledge, and it is comparatively difficult. Essay writing is used to test students' personal perspectives on the open questions and their ability to analyze the issue in a critical and deep way. The final examination covers the key and difficult points of the curriculum and is able to comprehensively and objectively evaluate students' systematic mastery of the course knowledge. Because the paper is in English version, and students are required to answer most part of questions in English, the examination is a challenge for many students.

Different from the mid-term examination and the final examination, whose scoring model is centesimal system, the quantitative evaluation criteria of group presentation, course essay, class participation and class attendance is designed in five-point rating scale. These evaluation methods more play a role in encouraging students to participate in curriculum learning. In addition, group presentation and course essay also encourage students to think hot and controversial world trade economic, political and legal issues in an open way, and train their ability of consulting professional documents. The proportion of the final examination score and daily performance (including mid-term examination, group presentation, course essay, class participation and class attendance) score are set to be 4:6. This allocation helps to improve students' curriculum grade reasonably, and is an incentive mechanism pushing students to learn actively so as to achieve the purpose of optimizing teaching effect.

\section{Conclusion}

A good evaluation mechanism should have the characters of reliability, validity, difficulty and discrimination. Whether the assessment method is scientific and appropriate is a possible factor that affects the students' learning initiative. [5] The ultimate goal of course examination is to serve teaching activities. The purpose of diversifying curriculum evaluation methods is to check students' mastery of the course through different assessment ways, so that teachers can accordingly improve teaching methods and improve teaching efficiency. Due to the appropriate incentives, students are willing to spend more time on course study. The diversification of evaluation methods of the WTO bilingual course for international economics and trade major students has achieved expected result.

\section{Acknowledgement}

In this paper, the research was sponsored by East China University of Political Science and Law Examination Reform and Innovation Project and East China University of Political Science and Law Undergraduate Curriculum Construction Project.

\section{References}

[1] Norman E. Gronlund, C. Keith Waugh. Assessment of Student Achievement [M]. Pearson, 2012. Preface.

[2] Blair R W. Innovative Approaches To Language Teaching [M]. Newbury House Publisher, Inc. Rowley Massachusetts, 1982.

[3] Chuanxiang Sun, Research on the Cultivation of Subjective Initiative in International Law Course Bilingual Teaching [J]. Contemporary Educational Theory and Practice, 20146 (2) 126-128.

[4] Yang Xiao \& Fang Li, How to Bring Students' Subjective Activity into Play in Bilingual Teaching [J]. Journal of Beijing Chemical Technology University (Social Science Edition), 2003 24 (3) 49-52.

[5] Wei Feng, Modern Educational Psychology [M], Southwestern Normal University Press, 2005. 475-480. 